\title{
Developing Mobile Application Tool To Support Technical Classification Service
}

\author{
M Rizqi Fitra $\mathrm{H}^{1, a, *}$, and M Fakhrur Rizal \\ ${ }^{1}$ Research and Development Division, Biro Klasifikasi Indonesia, Jakarta, Indonesia \\ a.mrizqi@bki.co.id,b.m.fakhrur@bki.co.id \\ *corresponding author
}

Keywords: $\quad$ Digitalization; Mobile; Surveyor; BKI iSee

\begin{abstract}
Biro Klasifikasi Indonesia (BKI) is the national entity which has the main portfolio on the classification of ships and floating structure. BKI is a recognized organization by the Indonesian Government and other flag states to classify marine transport and floating unit both for the domestic and international voyage. In order to support his Service Level Agreement (SLA), all aspects to support BKI's technical staff and field surveyors are required. This application aims to support and provide information needed by field surveyor and technical staff to make an analyzation and make a decision when they conduct the survey on the ship. The digitalization included rules and regulations, simple calculation, damage statistics and report, technical expert, and another menu. This also aims to be the bridge between a damage survey and damage statistics report, so that the experience solution could be given directly to the ship owner and/or ship operator in the fastest way. The functionality of digital solutions is shown by the statistical information based on user activity that is monitored from the servers. BKI iSee user raised significantly since launched until now already has 115 users.
\end{abstract}

\section{Introduction}

Biro Klasifikasi Indonesia (BKI) is the national entity which has the main portfolio on the classification of ships and floating structure. BKI is a recognized organization by the Indonesian Government and other flag states to classify marine transport and floating unit both for domestic and international voyage [1]. In order to support his Service Level Agreement (SLA), all aspects which support BKI's technical staff and field surveyors are required [2]. There were several supporting programs and application which already exists but most of the programs require can only be accessed within the company area.

The development of mobile-based application is necessary to equip surveyors and technical staff with the information needed while doing survey. So far information that can be accessed outside the company is very limited. This is not in line with the mobility of surveyors and technical staff who need fast information anywhere. Most of the other Classification Society such as Korean Register, DNV-GL, LR, etc already equipped their surveyor with such as application. 
Android is an open source operating system (open source). Called open source because the source code of the android operating system can be viewed, downloaded, and modified freely [3]. Android is an operating system for smartphones and tablets. The operating system can be illustrated as a bridge between devices (devices) and users, so users can interact with their devices and run applications available on the device. It is similar with Windows, Mac, or Linux but with different platform [4].

BKI iSee developed using android platform, due to majority of BKI's employee that already used android smartphone for daily life. BKI iSee is application that provide information about register, drawing status, rules, damage report, calculation, etc.

BKI iSee is an application developed by using those above facilities to provide the information needed by surveyors and technical staff such as register, drawing status, rules, damage report, calculation, etc. As with data commonly accessed on the computer, the use of android to access data has a major advantage that is the mobility of the gadgets which can be taken anywhere. Android is selected because of majority of BKI Surveyor and Technical Staff used smartphone with android platform.

\section{Overview of Development Process}

Developing process of this application is using questionnaire about what user needed to improve their performance as shown in "Fig.1". Questionnaire spread to BKI's field surveyor and technical staff, after collecting the input, team will analyse the possibility and make the design for user interface. If the design meets the expectation, programming process will be executed. If not, design will be revised until meet the expectation. After programming process finished, beta version will be released for certain user to analyze the performance and make data comparison between BKI existing system and data on device. If the beta version meets the expectation, BKI iSee will be released. If not, revision will be made until the beta version meets the expectation. The application stated running well if there are no bugs, and can show information properly to the field surveyor. If the application running well then released to all BKI staff, if it's not then will be checked programming process again.

In the development of this application there is also a Web Service in the form of PHP that aims to connect application with available databases. PHP is the most widely used script programming language today. PHP is widely used to program dynamic websites, although it is not possible to use for other uses. PHP is also used as the framework for many Web 2.0 applications due to its ability to handle databases easily and respond through common Web 2.0 protocols such as Extensible Markup Language (XML) and JavaScript Object Notation (JSON) [5]. The process of retrieving and displaying data from the database to the gadget is done through a bridge of PHP program where BKI iSee sends POST request to PHP [6] as shown in "Fig.2".

From PHP then forwarded to the database server in the form of query request data retrieval with a particular subject. Query is a kind of ability to display a data from a database which takes from the tables in the database [5]. To lighten the process, the query can also be set so that the only needed data is drawn without having to take the entire data from the table.

Data obtained from the database will be processed again by PHP to be packaged in json format. JSON is a compact format of computer data exchange. The format is text-based and used to represent data structures [5]. JSON format is a widely used in data exchange format by android application developers because the structure and file size transferred to the gadget is very simple and not too big and the process of data processing in android studio is very easy because Android Studio already provides facilities to split the json formatted data 


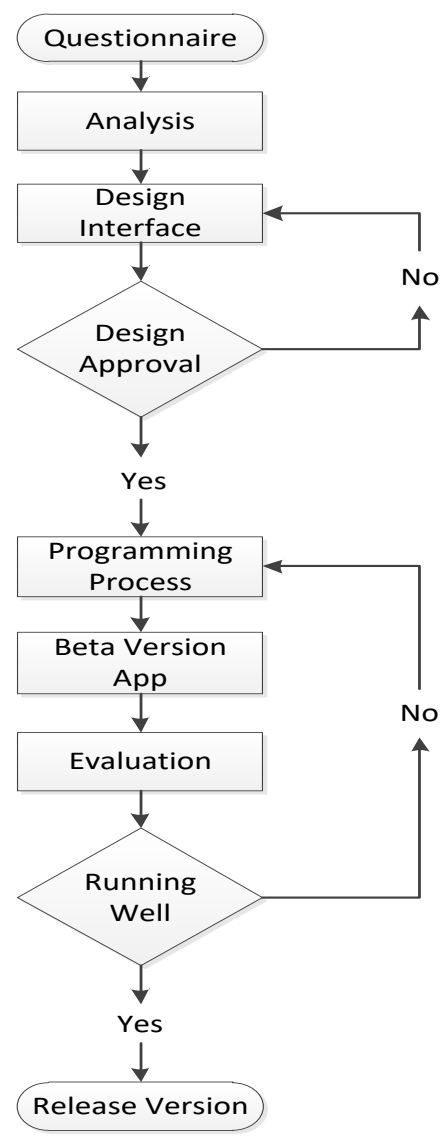

Figure 1: Flowchart Program Development Process

In addition, there is a facility from Google Firebase which is one of the features is Firebase Cloud Messaging which aims to provide notification to the user [7] when there is a message, news, or warning coming from the database to the application in real time.

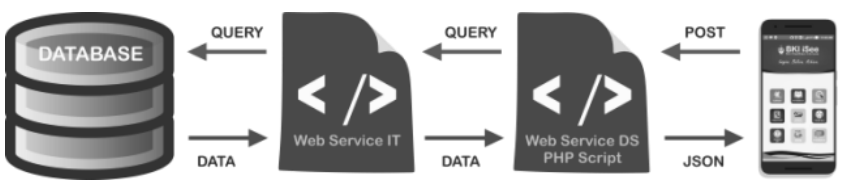

Figure 2: Scheme of data request

\section{BKI iSee Features}

From questionnaire decided menu needed for field surveyor and technical staff, BKI iSee has 9 main menus among others Survey, References, Tools, Directory, Damage Statistic, Profile, Vendor list, News, and Feedback

\subsection{Survey}

First menu in BKI iSee is Survey, consist of three submenus among others Ship Register, Drawing Status, and Audit. Ship Register provides information about ship register status, survey status, recomendation of ship, and principal dimension. Drawing Status describes the status of 
drawing approval. Audit is related to statutory matters. User can search using IMO number, ship name, or register number.

Validation is done by matching existing data registered ship on the BKI server so that the display of the survey menu became valid. With this menu information field surveyor can well known about status of ship, outstanding ship survey status before, and drawing approval status.

\subsection{References}

The References menu is used to view the BKI references required by the Surveyor and Technical Staff where there were Rules and other Work Instruction as shown "Fig.3". The system has been designed to allow synchronization with data in the server. If there is a new document update, BKI iSee will adjust automatically. There is also data security system by encryption methods for confidential Company documents.

Bookmark or Table of content inside the file has been added. User can open the desired page directly in accordance with the table of contents available as in the Rules file. Not all available files had tables of content so this page only works on pdf documents that already contained built in table of content.

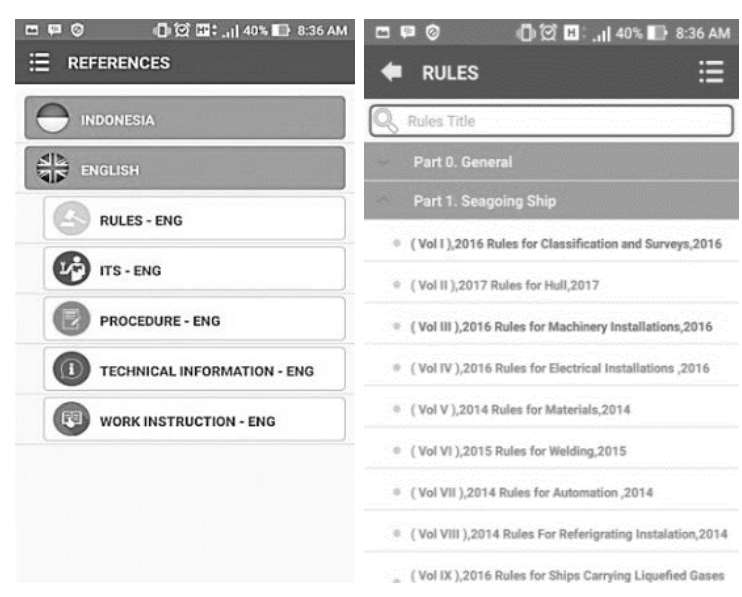

Figure 3: References menu

\subsection{Tools}

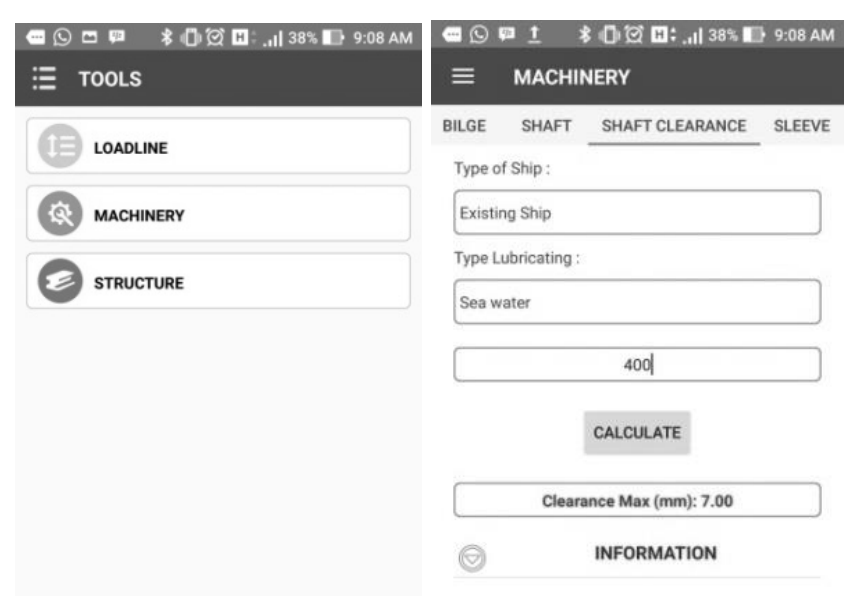

Figure 4: Tools Menu 
Tools have three sub menus Loadline, Machinery, and Structure. Tools are like simple calculator where user only input the blank field, and then the application will proceed the result by clicking the calculate button "Fig.4". It helps surveyor to quick calculate simply like calculator when they conduct survey. Field surveyor will resolve the problem quickly than before.

The calculation based on BKI Rules. Submenu Loadline provides the calculation of side scuttle, and freeing port. Machinery provides the calculation of rudder clearance, shaft dimension, shaft clearance, bilge pipe, and sleeve. Structure provides the calculation of modulus, bracket number, Znumber, and shaft bracket. All the calculation in this menu can also added in the future, based on field surveyor necessary.

\subsection{Directory}

Directory have three sub menus BKI Office, Surveyor Phone, and HSE. User can get information about phone number of BKI Office and branch from submenu BKI Office. Surveyor Phone provides information of BKI employee by doing search using employee NUP or name "Fig.5". Health Safety and Environment (HSE) provides information about HSE structure and responsible person in whole BKI branches and headquarters.

Field surveyor are frequently rotated to whole BKI branches. It helps to make field surveyor easy to know phone or email head office, whole branches contact, and whole BKI staff.

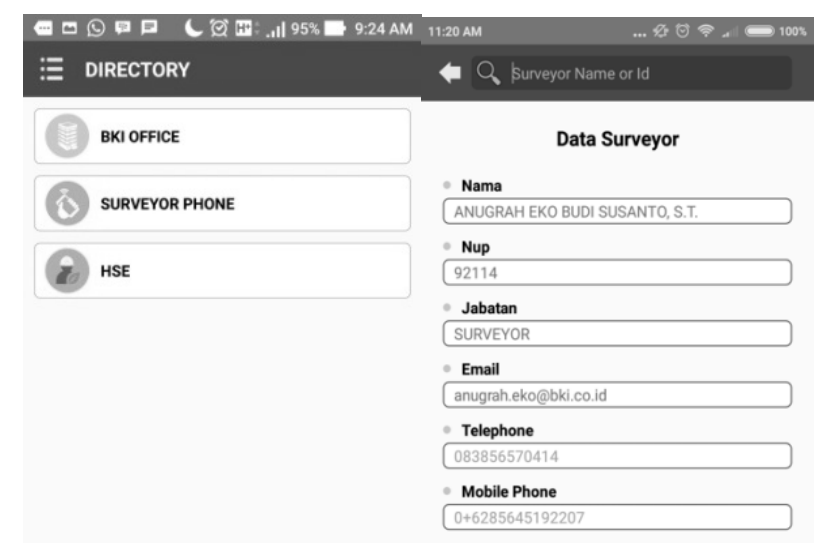

Figure 5: Directory menu

\subsection{Damage Statistics}

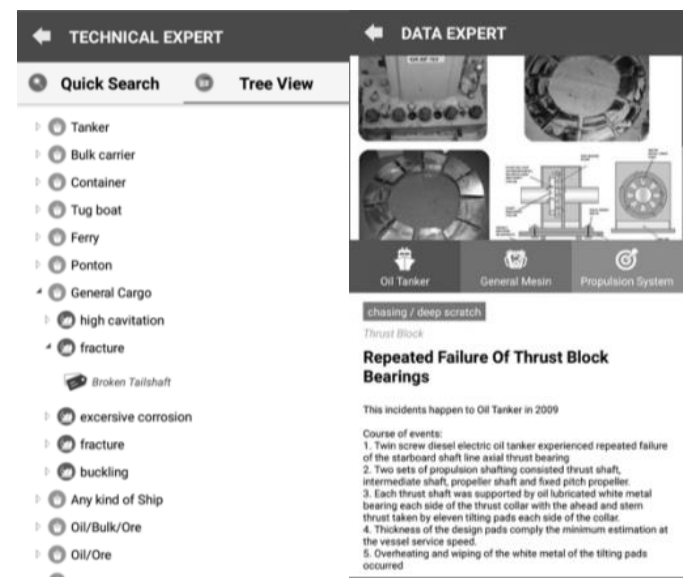

Figure 5: Damage Statistic 
Damage statistic consists of two sub menus damage statistic, and technical expert. Damage Statistic is a facility provided or presented in the application for surveyor to give input to the server regarding ship damage or accident so that research on it can be conducted or reviewed "Fig.6". Technical Expert is a collection of incidents, accidents, damage, and trouble-shooting which has been reviewed by BKI Technical Expert team. Until now the Technical Expert output came from sources such as IACS, other Class Society, and BKI Research and Development publication.

Inputting Technical expert data was done through a special web of Research and Development Division which will be entered into database and this application will pull the data from the database.

\subsection{Profile}

Profile consists of information about personal user, where user can customize their preferred password, and application "Fig.7". In this menu user can get information about delegation of survey from submenu SPS. It contains the list of individual delegated survey scheduled including completed survey, on progress survey, and booking survey. When there is new delegated survey, there will be a notification through firebase system for the user as a reminder.

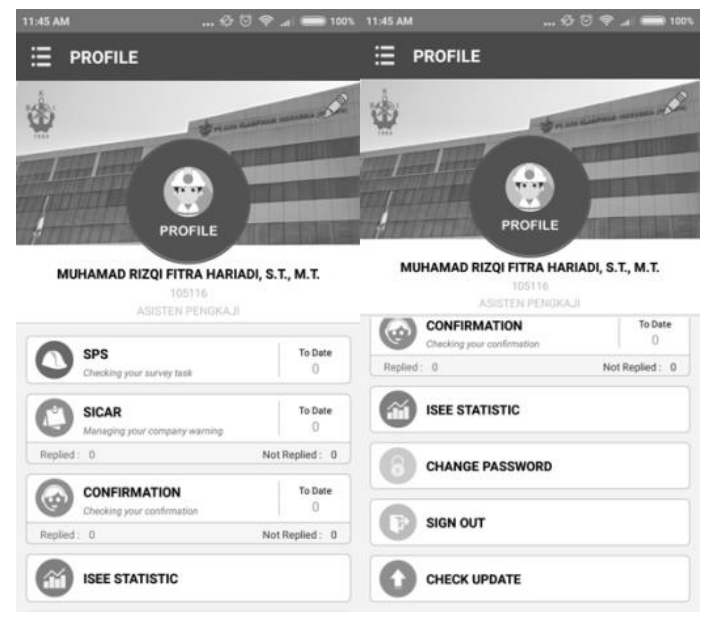

Figure 7: Profile menu

\subsection{Vendor List \& News}

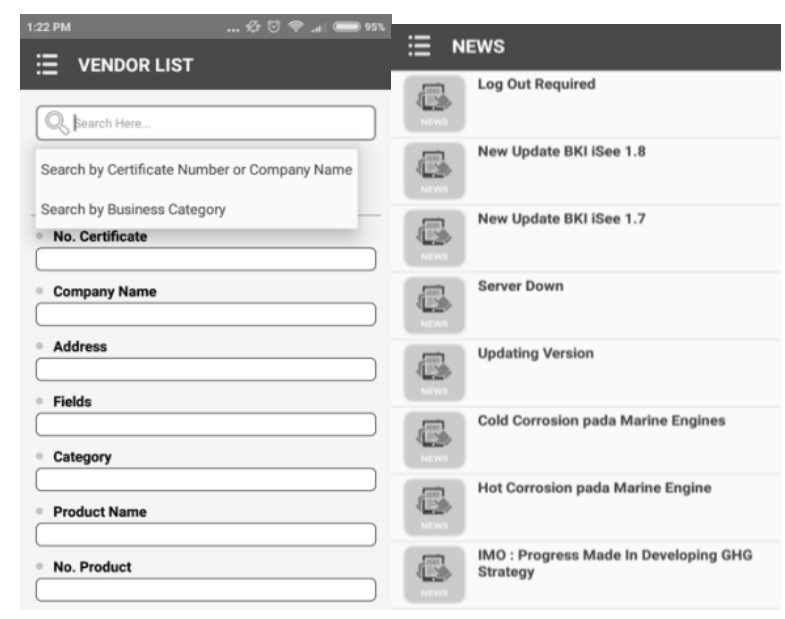

Figure 8: Vendor list \& News 
BKI not only provide a certificate for ship but also material component installed on the ship must be certified by BKI. Vendor list menu provides information about material and component companies which already certified by BKI. Field surveyor can search the company fill the search field and category "Fig. 8 ".

BKI iSee doesn't only provide information about BKI product, but also provide a news update in the maritime industry, international regulations, maintenance of BKI iSee server, ship accident, and etc. It helps for field surveyor more aware of up to date information not only rules and regulations on BKI but also international regulations, and ship accident.

\subsection{Feedback}

Feedback divide by two submenus send feedback and response "Fig.9". User can give a suggestion and critics about the application, user just chooses the category about their feedback and describe their comment by 500 words. Response submenus, user can read the answer about their previous feedback from BKI iSee team. All feedback from user is collected and answered by BKI iSee team. From collected feedback, BKI iSee team will analyze to develop as user suggestion in feedback.

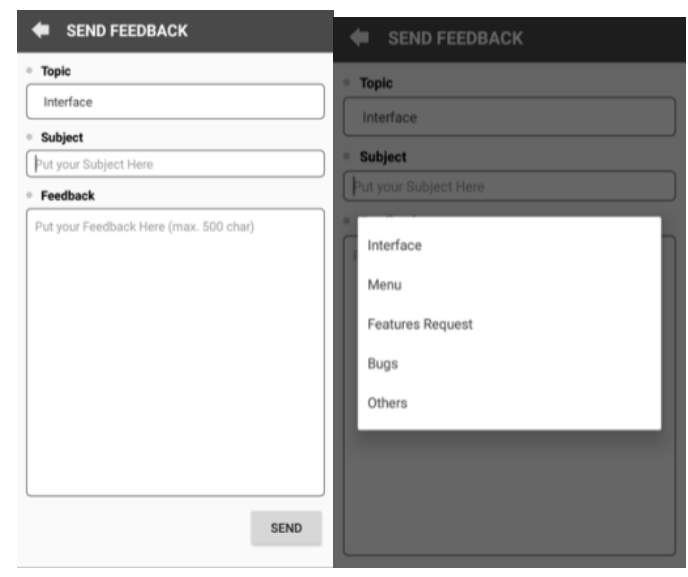

Figure 9: Feedback

\section{User Experience}

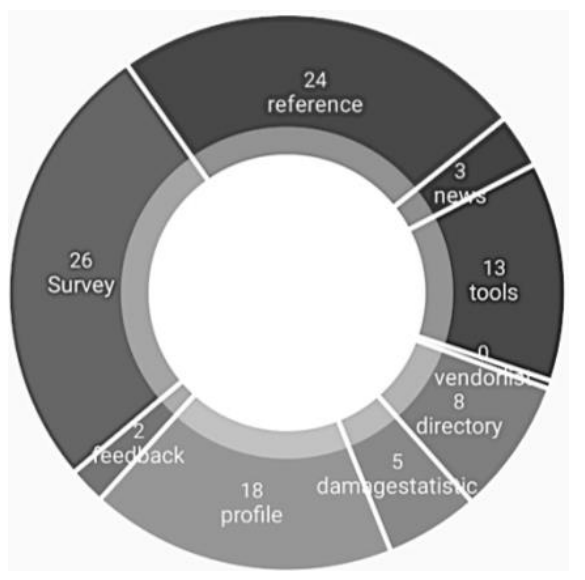

Figure 10: User Experience 
Since launch in June 2017 until now, BKI iSee has 115 users. "Figure 10" shows the user experience using BKi iSee. From that figure we know that Survey, References, Tools, and profile are menu which is often accessed by user. From that data can analyze the behavior of the user when using this application. Survey menu has the highest percentage, indicates that the basic information of ship register, drawing, and statutory is essential for field surveyor when doing their job.

References became the second highest percentage, indicates that rules, and other document regarding classification is needed by the user. Surveyor doesn't need to bring handbook.

Profile has good percentage shows that user especially surveyor often use this menu to check their delegated survey, sicar, and confirmation. With notification if there is new SPS to field surveyor, make field surveyor can scheduled their survey. Tools became number 4 indicates this menu is used by user to calculate some cases on board.

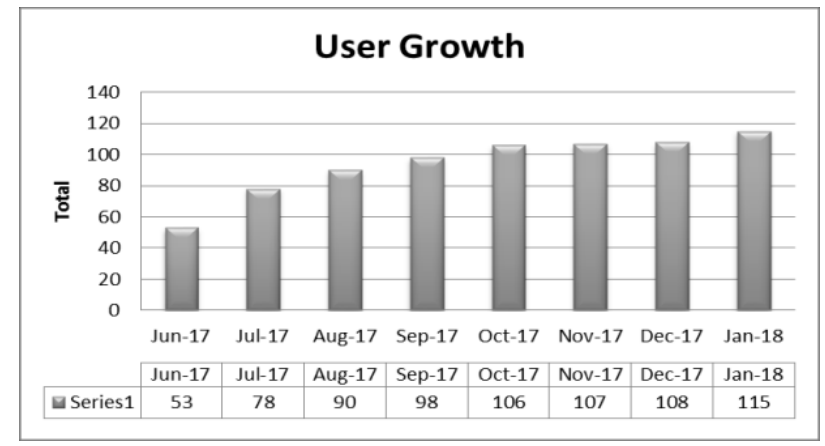

Figure 11: User Growth

Since this application had been launched (June 2017) until now (January 2018), the user increases significantly "Fig 11". Where the highest user registered raise from June to July, from 53 user to 78 user. Month by month BKI iSee user raised are stable it's proof if BKI iSee worthed become mandatory as an application to use for field surveyor and technical staff.

\section{Conclusions}

BKI iSee as a mandatory application has 115 active members and still increase today. Advantages of BKI iSee for internal BKI is field surveyor, and technical staff can easy to get information about ship will besurveyed, and up to date rules and regulations from their mobile phones. Advantages for external BKI is owner can satisfied with field surveyor services, from on time survey scheduled, and a transparent decision from field surveyor.

BKI iSee provided nine menus survey, references, tools, directory, damage statistic, profile, news, vendor list, and feedback. User favorite menus are survey, references, profile, and tools.

\section{References}

[1] Direktorat Jenderal Perhubungan Laut, DJPL (2016), Surat Keputusan Direktur Jenderal Perhubungan Laut Nomor PK.204/1/3/DJPL-16 tentang penunjukan Biro Klasifikasi Indonesia (Persero) sebagai Recognized Organization untuk melaksanakan survey dan sertifikasi Statutoria atas nama Pemerintah pada kapal Berbendera Indonesia, 2016

[2] BKI, company profile, 2017

[3] G. Dini, F. Martinelli, I. Matteucci, M. Petrocchi, A. Saracino, D. Sgandurra,A Multi-criteria-Based Evaluation of Android Applications, in:Trusted Systems, Vol. 7711 of LNCS, Springer Berlin Heidelberg, 2012,

[4] pp. 67-82Satyaputra, Alfa, Eva Maulina A., A standard for developing secure mobile applications, 2013

[5] Jason Andress, Ryan Linn, Introduction to web scripting with PHP, 2017

[6] Mario Heiderich, Eduardo Alberto Vela Nava, Gareth Heyes, David Lindsay, Web Application Obfuscation, 2011

[7] Wartella, E. (2015). Educational apps what we do and do not know. Psychological Science in the Public Interest, $16(1), 1-2$. 